\title{
SOFTWARES DE SIMULAÇÃO NO ENSINO DE QUÍMICA: UMA REPRESENTAÇÃO SOCIAL NA PRÁTICA DOCENTE
}

\section{Elda Silva do Nascimento Melo João Ricardo Freire de Melo}

\begin{abstract}
RESUMO
Atualmente não é mais possível compreender o ensino centrado apenas no professor, antes considerado o único detentor do conhecimento. O processo de ensino-aprendizagem deve ser algo dinâmico que estrutura, e é estruturado de acordo com as relações forjadas em seu desenrolar. Assim, ferramentas como os softwares de modelagem surgem para otimizar e auxiliar nesse processo. Nesta perspectiva, o presente trabalho busca refletir sobre as mudanças conjunturais que levam os professores a adotar novas posturas para um melhor desenvolvimento do processo de ensinoaprendizagem. Em decorrência destas transformações, os docentes têm adotado novas formas de ensinar, que abrem espaço ao uso das novas tecnologias, cujas contribuições são inegáveis, especialmente, no ensino de Química. No entanto, em face da falta de preparo, do medo de mudanças e do modo acelerado como essas mudanças têm ocorrido, os professores da referida disciplina têm construído uma representação social acerca do uso das novas tecnologias, notadamente, dos softwares de modelagem, que tem tornado lento e confuso o processo de informatização do ensino de química. Neste sentido, cremos na pertinência deste trabalho, pois, essa discussão pode nos fazer compreender em que medida os professores de Química podem utilizar criticamente as novas tecnologias, aprimorando a sua prática.
\end{abstract}

PALAVRAS-CHAVES

Educação em Química, Softwares de Modelagem, Representação Social.

\section{SIMULATION SOFTWARE IN THE TEACHING OF CHEMISTRY: A SOCIAL REPRESENTATION IN THE TEACHING PRACTICE}

\begin{abstract}
In our modern society it is no longer possible to think of a teaching focused exclusively on the teacher figure, once considered the sole holder of the knowledge. The teaching-learning process must be something dynamic that structures, but that is also structured according to the relations which are forged in its developing. So, tools as the modeling softwares appear to optimize, improve and help this process. In this perspective, this work has as its goal to wonder about the conjunctural changes which have caused the teachers to adopt new attitudes in order to achieve a better development of the teaching-learning process. As in consequence of these changes, the teachers are pushed to adopt new ways in their teaching, which, in turn, foster the usage of the new technologies, whose contributions are undeniable, specially in the Chemistry field. However, due to the lack of training, the fear of changes and the very fast way these changes have occured, the teachers of the mentioned discipline have built a social representation of the usage of the new technologies, notably, of the modeling softwares, which have at least turned the informatization process of the teaching of Chemistry slower and more confusing. Thus, we believe in the relevance of this work, since this discussion can make us understand how the teachers of Chemistry can use the new technologies in a critical way, enhancing their experience.
\end{abstract}

\section{KEYWORDS}

Education on Chemistry, Modeling Softwares, Social Representations 


\section{INTRODUÇÃO}

É indubitável o processo de transição que vem ocorrendo no âmbito educacional vigente, em face do grande desenvolvimento tecnológico, que por sua vez tem também, acarretado inúmeras transformações em outras esferas tais como a política, a econômica, a social, a cultural e a científica. Com isso o ensino tem exigido dos profissionais uma contundente transformação, caso contrário, estará sob pena de tornar-se obsoleto, ultrapassado e repassador de receitas que não mais funcionam. Nesta perspectiva, torna-se imperativo a eclosão de novas formas de aprender e ensinar, que requerem novas concepções do fazer pedagógico. Assim, evidencia-se a necessidade do uso dos computadores, os quais têm se estabelecido como mediadores do processo de ensino-aprendizagem, exigindo do professor novas habilidades e competências. Porém, é preciso enfatizar que se deve ir além de requerer professores treinados para fazerem uso da racionalidade instrumental e de utilizá-lo como mero instrumento e reprodutor de uma prática pedagógica pautada em uma formação que prioriza a transmissão dos conteúdos em detrimento de sua real importância para a construção social do indivíduo. Pois como afirma Lèvy (1999, p. 34) “A questão central não está na mudança do ensino tradicional para os mediatizados por tecnologias, mas na transição de uma educação e uma formação estritamente institucionalizada para uma situação de troca de saberes".

Entendemos que a informação está disponível em várias instituições, no entanto, a escola é o lugar por excelência de sua produção e proliferação. Faz-se necessário que esta abra suas portas no sentido de situar em seus espaços as novas tecnologias, as quais auxiliarão no processo de produção de conhecimento, pois a instituição educacional que assim não o fizer, estará sujeita à marginalidade do desenvolvimento científico.

Diante desse quadro, restringimos nosso universo de investigação aos professores da disciplina de Química, buscado analisar até que ponto estão envolvidos com a utilização das novas tecnologias (como os softwares de modelagem) em seu fazer pedagógico e se estão preparados para internalizar criticamente tais inovações tecnológicas, colocando-as em prática num constante processo de reflexão. Para realização desta análise nos utilizamos da teoria das Representações Sociais, apresentada por Moscovici (1978), que tem como premissa a identificação da ‘visão de mundo’ que os indivíduos ou grupos têm e utilizam para agir e para 
tomar posição, sendo indispensável para a compreensão da dinâmica das interações sociais e para a clarificação dos determinantes das práticas sociais (ABRIC,1994).

Ao procedermos uma análise pautada na teoria das representações sociais objetivamos compreender, ainda que 'a priori’ apenas num plano teórico, a relação que os docentes de Química têm estabelecido com as novas tecnologias, constatando assim, como têm lidado com a necessidade de adotá-las em virtude da irrefutável contribuição advindas de sua utilização. buscamos ainda, investigar se os referidos docentes têm tido acesso a hardware e aos diferentes tipos de software de simulação e, nesse caso, se houve a tentativa de se trabalhar de forma integrada dentro de uma perspectiva construtivista de aprendizagem. Averiguamos também que nível de qualificação tais docentes têm adquirido para empregar na sua prática pedagógica os softwares de simulação.

\section{O AMBIENTE DE ENSINO PAUTADO NO USO DAS NOVAS TECNOLOGIAS: UM SALTO QUALITATIVO EM PROL DA EDUCAÇÃO}

Neste momento de incríveis mudanças tudo e todos foram atingidos de alguma forma e a educação não seria exceção. Nunca houve uma demanda tão grande por escolas e pelo ensino formal, em qualquer nível. A explosão demográfica experimentada nos últimos anos provocou uma disparidade entre oferta e demanda no ensino formal. A escola não conseguiu acompanhar tão rapidamente a evolução da tecnologia na sociedade, nem em termos quantitativos, nem qualitativos. Está claro que precisamos tomar atitudes em relação à melhoria da educação em todos os sentidos. Ela precisa evoluir em tecnologia, em qualidade e em abrangência. É exasperante a constatação dos índices de analfabetismo no Brasil e no mundo, em pleno século XXI. É necessário, portanto, buscar soluções que utilizem técnicas capazes de ampliar o esforço pedagógico dos professores e dos formadores, no sentido de atenuar essa situação calamitosa.

Os ambientes de educação apresentam uma diversidade de ferramentas que podem promover essas soluções tanto em comunicação síncrona como na assíncrona: recursos audiovisuais, Ensino Assistido por Computador através de multimídia interativa, E-mail, grupos de discussão, World Wide Web - WWW, download, vídeo e áudio sob demanda, chat, teleconferência - áudio e videoconferência. Todas essas possibilidades técnicas, pertinentes de 
acordo com o conteúdo, à situação e às necessidades do "ensinado", podem ser pensadas e já foram amplamente testadas e experimentadas.

Porém o ambiente de ensino pautado em seu uso pressupõe uma interação onde os professores aprendem ao mesmo tempo em que os estudantes, e, atualizam continuamente tanto seus saberes "disciplinares" como suas competências pedagógicas.

A partir daí, a principal função do professor não pode mais ser apenas a difusão dos conhecimentos, que agora é feita de forma mais eficaz por outros meios. Sua competência deve deslocar-se no sentido de incentivar a aprendizagem e o pensamento.

O professor torna-se um animador da inteligência coletiva dos grupos que estão a seu encargo. Sua atividade será centrada no acompanhamento e na gestão das aprendizagens: o incitamento à troca dos saberes, a mediação relacional e simbólica, a pilotagem personalizada dos percursos de aprendizagem etc. (Lèvy, 1999, pág. ).

A apreensão de novos saberes através das novas tecnologias deve ser contemplada e em sendo a escola o local por excelência da promoção de novas aprendizagens, faz-se necessário à inserção de ferramentas como os softwares de simulação em sua metodologia de ensino. Uma forma adicional de uso de computadores no ensino é a que faz com eles simulações de experiências. Em lugar de o aluno observar a realidade de modo fragmentado como nos laboratórios de química e física, as experiências são simuladas na tela do computador. Apesar do medo e da resistência de alguns professores de química, esses instrumentos podem representar um grande salto qualitativo na aquisição dos conteúdos da disciplina, que de acordo com Ribeiro e Greca (2003, p. 544),

É uma ciência essencialmente simbólica, isto é, trabalha com símbolos para representar elementos e fenômenos, e o aluno, além de ter que conhecer tais símbolos, ainda deve ter a capacidade de transformar determinada forma de representação em outra equivalente, de maneira mais apropriada.

As autoras explicitam que para explicar e explorar fenômenos, processos e idéias abstratas, bem como para proporcionar aos alunos o desenvolvimento da capacidade de representação em seus distintos níveis e auxiliá-los na competência representativa, os pesquisadores têm sugerido várias abordagens pedagógicas, dentre as quais tem se destacado o uso de simulações computacionais. Assim, os softwares de simulação podem ser de grande 
utilidade, no sentido de que os educadores consigam proporcionar condições aos alunos de compreender os fenômenos estudados.

Ainda segundo Ribeiro e Greca (2003), simulações computacionais podem ser classificadas genericamente como conceituais e operacionais. As conceituais se referem a conceitos, princípios e fatos relacionados aos eventos simulados, como simular a estrutura de uma molécula. Já as operacionais incluem seqüências de operações e procedimentos que podem ser aplicados aos sistemas simulados, a exemplo disso, temos a simulação de uma esterilização e manuseio de um equipamento ao realizar um determinado procedimento.

Nesta perspectiva, as autoras colocam que, em uma simulação, o comportamento deve representar o funcionamento do sistema real, de acordo com as teorias ou modelos que o descrevem, ou seja, são representações de um sistema que a teoria supõe ser real, que possibilitam interações sem as limitações ou perigos que o sistema real possa ter.

Vieira classificou os softwares educacionais para Educação Química, encontrados entre 1978 e 1994 no periódico Journal of Chemical Education, em 12 categorias:

- Aquisição de dados e análise de experimentos: esses programas podem fazer a organização e a análise dos dados do experimento, traçando gráficos e apresentando várias tabelas com estatísticas diferentes, conforme a necessidade.

- Base de dados (BD) simples: conjunto organizado de dados com uma lógica que permite rápido acesso, recuperação e atualização por meio eletrônico.

- BD / Modelagem: apresentam características comuns aos de base de dados simples, isto é, utilizam os mesmos recursos de acesso e gerenciamento de dados e das modelagens, que executam normalmente uma grande quantidade de cálculos matemáticos.

- BD / Hipertexto e/ou Multimídia: as bases de dados já existentes para PC’s com os recursos de som e imagens coloridas.

- Cálculo computacional: resolvem equações matemáticas dos mais diferentes tipos, realizam inúmeros cálculos, como por exemplo, os relativos a $\mathrm{pH}$, propriedades termodinâmicas, equilíbrio químico, análises qualitativas e quantitativas, etc, propiciam uma ponte entre o que 
se tem, por exemplo, equações e dados experimentais, e o que se deseja, geralmente informações e resultados estruturados na forma de tabelas e gráficos variados.

- Exercício e prática: apresentando um conjunto de exercícios ou questões para o aluno resolver.

- Jogo educacional: programas de jogos, que permitem que o aluno desenvolva a habilidade de testar hipóteses, funcionando como se fosse um constante desafio à sua imaginação e criatividade.

- Produção de gráficos e caracteres especiais: muito úteis no ensino de certos conteúdos de química.

- Simulação: programas que trazem modelos de um sistema ou processo.

- Sistema especialista: programas de grande complexidade e custo, usados em diagnósticos e pesquisas.

- Tutorial: programa que ensina ao aluno uma determinada área de conhecimento, tendo a vantagem de ser mais dinâmico e animado (sons e imagens) que um livro texto.

- Outros: tipos de programas que, por sua especificidade e pequena quantidade, não puderam constituir uma classificação específica.

As simulações são feitas através de um software que abriga um modelo prédeterminado, construído pelo professor ou pesquisador, onde o aluno não tem acesso, deste modo, não pode questioná-lo ou modificá-lo. Nesse sentido, questiona-se em certa medida até que ponto as interações existentes nesse processo permitem realmente que o aluno interaja com o programa.

Em um artigo intitulado "O uso do computador num projeto construtivista de educação” a autora Regina de Oliveira Heidrich expõe o seguinte pensamento: 
O uso do computador expressa-se em um contexto de contínua interação. Nesse sentido, o computador não é apenas um instrumento que prolonga nossos poderes de comunicação ou de processar informações: realiza operações e interpreta informações de modo correspondente ao nosso. Com isso possibilita uma qualidade de interação, que tem valor de desenvolvimento. Piaget chamava essa qualidade dialética de interação de "formas de interdependência". Trata-se de uma interação em que os elementos devem funcionar ao mesmo tempo, como "todo" e como "parte", ou seja, devem atuar de forma interdependente. Como "todo" porque são "responsáveis" por suas decisões, e como "parte”, porque sua ação depende da ação de um outro. Não é assim, entre nós e um programa de computador? Não deveria ser assim, também, na escola?

Sendo assim, os softwares apesar de não serem projetados para que o aluno os modifiquem, proporciona um tipo de interação com o programa que permite ao aluno visualizar eventos que acontecem em nível microscópico para construir posteriormente um modelo mental do fenômeno macroscópico, fazendo assim suas próprias inferências e previsões.

A melhor forma de aprender é interagir, seja com a máquina, com a tecnologia, com as telecomunicações, com os colegas ou mesmo com os professores. Aos alunos interessa tanto o aprendizado por instrução como por descoberta. Não podemos dispensar nem um recurso nem outro. O que precisa haver, é a ideal comunhão entre esses elementos que estimulam o aprendizado. Se o professor se aliar adequadamente aos recursos que lhe estão disponíveis, todos têm a ganhar. É preciso apenas, deixar a ansiedade de lado e perceber que não se trata de fazer uma opção exclusiva. Não é a escola tecnológica que vai extinguir a escola clássica.

Kozma (1997) afirma que os meios e os métodos juntos influenciam a aprendizagem, sugerindo que a visão de recursos computacionais como geradores de métodos deve se pautar em uma nova visão, a de que métodos e recursos juntos podem facilitar a construção do conhecimento e do senso crítico dos alunos.

É possível combinar os elementos que temos de boas contribuições nas várias vertentes e criarmos novos horizontes em qualidade de ensino. Vamos trazer para dentro da escola convencional os avanços conseguidos com a tecnologia. É bem verdade que esse salto de qualidade exigirá dos provedores de conhecimento e de mídia um domínio maior de suas potencialidades e eficácia, porém esse é um preço que terá que ser pago, mas que tem como prognóstico uma escola que busca desenvolver seus alunos de forma holística, inserindo-os num mundo onde a tecnologia trabalha em prol da educação. 


\section{UMA REPRESENTAÇÃO SOCIAL DO USO DOS SOFTWARES NO ENSINO DE QUÍMICA: IMPLICAÇÕES PARA A PRÁTICA DOCENTE}

Como já mencionamos a educação vem sofrendo profundas transformações em sua forma e conteúdo ao longo das últimas décadas devido à introdução de uma série de novos fatores tecnológicos e comportamentais, tanto no âmbito nacional quanto no internacional. A introdução do rádio, da televisão e, mais recentemente, do computador e da Internet nos meios tradicionais de educação vem provocando uma inquietação nos professores e pesquisadores da educação. Uma série de pesquisas está sendo realizada visando adaptar antigas técnicas de ensino às novas tecnologias e às novas demandas surgidas nesse período.

Sendo assim, para abarcar a dimensão micro desta discussão, ou seja, a forma como os professores de lecionam a disciplina de Química têm apreendido estas questões, lançamos mão da teoria das representações sociais, por esta ser considerada a teoria do senso comum.

O conceito de Representações Sociais foi introduzido na Psicologia Social por Moscovici (1978). Ele afirma que a reprodução das propriedades de um determinado objeto pelo ser humano não é o reflexo de uma realidade externa perfeitamente acabada, mas uma verdadeira construção mental do objeto que implica reconstruí-lo dentro de um contexto de valores, noções e regras. A representação social é elaborada pela atividade simbólica do indivíduo que, assim, apreende o seu ambiente. Portanto, só pode ser compreendida se também for buscada a história individual relacionada à história da sociedade a qual o indivíduo pertence. Ela é o processo e o produto da relação entre a atividade mental e a práxis social (Abric, 1994).

Moscovici, reconhece que a representação social é um conjunto de conceitos, explicações e afirmações que se originam na vida diária, no curso de comunicações interindividuais. O universo das representações sociais é o universo consensual, sendo que a linguagem desempenha um importante papel, facilitando associações de idéias, reconstruções de regras e valores, onde o desconhecido passa, simbolicamente, a conhecido. Distingue representação social de opinião, atitude e imagem, que são formas mais simples de expressão, e que estão fora das intenções dos indivíduos. Isto é, alguém pode expressar uma opinião pela imposição social, o que não significa que incorpore o discurso à prática social. 
Os dois processos básicos, segundo Moscovici, da representação social são a “ancoragem” e a "objetivação”. Ancorar é trazer para categorias e imagens conhecidas o que não está ainda classificado e rotulado. É transformar o que é estranho em algo familiar, ou em outras representações que, por sua vez, passa a fazer parte do sistema de integração entre o indivíduo e o mundo social porque o que é comum ao grupo permite compartilhar comunicação e influenciar a ação.

Objetivar é transformar uma abstração em algo quase físico. Objetivação é o processo através do qual se cristaliza uma representação: noções abstratas são transformadas em imagens, cujo conteúdo interno após descontextualizar-se forma um núcleo figurativo para, por fim, transformar as imagens em elementos da realidade. Importante também é salientar que para qualificar uma representação como social é preciso definir o agente que a produz e enfatizar que a representação tem como função contribuir exclusivamente para os processos de formação de condutas e de orientação das comunicações sociais.

Jodelet acrescenta que a representação social é o ponto de intersecção do psicológico e do social. Constitui-se a partir das experiências, dos conhecimentos, informações e modelos de pensamentos transmitidos, cotidianamente, através da tradição, educação e comunicação social. Toda representação define-se por seu conteúdo, o qual tem como elementos, conceitos e imagens criados por alguém a respeito de um objeto, de forma a se relacionar com outras pessoas.

As representações sociais, na ótica da psicologia social, constituem uma forma de conhecimento prático - o saber do senso comum - que tem dupla função: estabelecer uma ordem que permita aos indivíduos orientarem-se em seu mundo material e social e dominá-lo; e possibilitar a comunicação entre os membros de um determinado grupo. (Spink, 1993).

As reflexões a respeito de representação social levam a concluir que o ser humano, objeto e sujeito da história, desenvolve-se através de processos de comunicação, onde a representação social, dinamicamente, estrutura e é estruturada. Para analisar as representações que um indivíduo tem do mundo onde vive, ou viveu, é necessário captar a visão que tem de seu mundo, sabendo que tal visão dependerá do lugar ocupado por si em relação aos outros. Esta relação não é apenas objetiva, mas também subjetiva, na qual um se confronta com o outro e, ao mesmo tempo, com a imagem que elabora do outro. 
A vida social age sobre o comportamento do indivíduo a partir do exterior. Estruturas e normas criadas por diferentes indivíduos materializam-se em realidades autônomas que passam a independer daqueles que as criaram.

É preciso enxergar o ser humano também como sujeito ativo na sociedade, enfatizando-o enquanto ser comunicativo, criador de símbolos e significados. A comunicação é uma necessidade humana básica e o ser humano utiliza-se dela em todas as situações de sua vida para partilhar com os demais suas experiências, constituindo sua identidade.

Embasados nas definições acima buscamos demonstrar como o conteúdo representacional acerca do uso das novas tecnologias, dentre elas o software de modelagem, tem sido construído no imaginário dos docentes de química.

O uso de computadores tem adquirido suma importância nos dias atuais, já que se faz presente em todos os setores da sociedade em escala universal. No que se refere às escolas têm se tornado uma poderosa ferramenta educacional, sendo considerado até mesmo vital para uma futura ascensão social, essencial em qualquer currículo.

A divulgação do conhecimento produzido e o acesso a informação, os quais têm se constituído em pilares da educação moderna, acontecem de forma cada vez mais ágil e, com isto, os critérios de perenidade e permanência dos conhecimentos acumulados somam-se ao critério da atualidade. O novo conhecimento produzido está disponível em quantidade, profundidade e com uma rapidez capaz de surpreender a quem desejar conhecê-lo.

A constatação desta situação tem trazido desafios aos educadores. Conhecer as diversas tecnologias da informação e da comunicação e saber usá-las para vencer os desafios impostos em cada realidade educacional específica, estar aberto às mudanças, procurar entendê-las e ter disposição de se reciclar para atuar em cenários diferentes, são atitudes condizentes com a atual conjuntura.

Outro aspecto que pode ser apontado como conseqüência da adoção deste novo paradigma diz respeito às questões de poder e autoridade associados à relação professor/aluno/conhecimento. Uma das tendências mais utilizadas desde o início do século XX até os dias de hoje denomina-se de Pedagogia Tradicional, caracterizada por centrar-se no ensino, considerar o professor o detentor do conhecimento e o único responsável pelo processo de aprendizagem. No entanto, ao longo dos anos essa vertente sofreu críticas e 
passou por inúmeras transformações em face do processo de conscientização de tem permeado o espaço escolar. Sendo assim, o que prevalece hoje na maioria das escolas é uma perspectiva dialética que vê o professor e o aluno em posição de igualdade, em que ambos detém conhecimentos específicos, diferenciados e relevantes, e que, em igual medida, têm acesso a novas e heterogêneas informações.

De acordo com este último postulado, os softwares de simulação têm surgido como uma nova opção no ensino da química, visando substituir as representações pictóricas, esquemáticas e os modelos estáticos anteriormente utilizados por ferramentas que proporcionam visualização de representações de modelos dinâmicos, proporcionando condições aos alunos de desenvolverem a compreensão conceitual dos estudos, sem que haja apenas o uso mecânico dos conceitos que envolvem os fenômenos estudados.

Deste modo, é patente que os softwares de simulação podem trazer para o estudo da química um grande beneficio. Por outro lado, verifica-se que os docentes da área não se encontram devidamente seguros e preparados para utilizá-los devido ao um sentimento de medo desses em relação a essa nova tecnologia. Há ainda por parte de cientistas, pedagogos e administradores escolares que querem produzir resultados a curto prazo, muita ansiedade em torno de saber o que o computador será capaz de fazer pela educação. Alguns que estudam a educação querem ver-se livres dos métodos tradicionais e substituir tudo o que se estabeleceu nos séculos passados por uma panacéia cibernética, capaz de resolver todos os seus problemas. Está certo que a área de educação é a área que mais pode beneficiar-se destas novas tecnologias, mas a transformação está apenas começando. Diversas experiências se frustraram devido à falta de preparo e de planejamento em longo prazo. De acordo com Hawkins (1995), a tecnologia foi considerada uma solução a parte para um problema. Julgava-se que seria apenas uma questão de aperfeiçoá-la para poder mudar tudo. Isto é absolutamente equivocado.

Este equívoco, pelo que pudemos perceber, não é raro no meio educacional, e não seria diferente com os professores da química, o que nos leva a inferir que talvez esta visão, que acabou sendo frustrada, tenha contribuído ainda mais para que os docentes de uma forma geral, e, especialmente os de química, construam uma representação equivocada a respeito das novas tecnologias. 


\section{REFERÊNCIAS}

ABRIC, J. C. O estudo experimental das representações sociais In: JODELET. D. As representações sociais. Rio de Janeiro: EdUERJ. p. 155-173, 2001.

EICHLER, M.; Pino, J. C. Computadores em educação química: estrutura atômica e tabela periódica. Revista Química Nova, v. 23, n.6, 835-840, 2000.

GARCÍA, R. B. La Educacíon virtual. Desafio para la construccíon de culturas e identidades [on line]. Disponível na internet: URL < http://investigacion.ilce.edu.mx/> Acesso em: 08/02/2005.

DOMINGOS SOBRINHO, M. O sentido da educação para os educadores: capital simbólico e campo educacional no RN. DEPED/UFRN, 1997/98.

JODELET, D. Representações sociais um domínio em expansão. In: JODELET, D. (Ed.) Les représentations sociales. (1989) Paris. PUF. (p. 31-61) (texto digitado, tradução livre de grupo de alunos PROGEDI/UFRN).

LÈVY, P. Cibercultura. São Paulo: Editora 34, 1999.

MORGON, Nelson H. Computação em química teórica: informações técnicas. Revista Química Nova, v. 24, n. 5, 676-682, 2001.

MOSCOVICI, S. A representação social da psicanálise. Zahar Editores, Rio de Janeiro, 1978.

MUÑOZ, P. Á. Aprendizaje con nuevas tecnologías: paradigma emergente[on line]. Disponível na internet: URL <http://investigacion.ilce.edu.mx/> Acesso em: 08/02/2005.

MUÑOZ, P. A. Consideraciones pedagógicas para la incorporácion de la computadora como herramienta de apoyo al proceso educativo [on line]. Disponível na internet: URL $<$ http://investigacion.ilce.edu.mx/>. Acesso em: 08/02/2005.

KOZMA, R. B.; RUSSELL, J. J. Res Sci. Teaching 1997, 34,949.

RIBEIRO, Â. A.; GRECA, I. M. Simulações computacionais e Ferramentas de Modelização em Educação Química: uma Revisão de Literatura Publicada. Revista Química Nova, v. 26, n. 4, 542-549, 2003.

SÁ, C. P. Sobre o núcleo central das representações sociais. Petrópolis, RJ: Vozes, 1992.

SPINK, M. J. O estudo empírico das representações sociais. In: (Ed.), O conhecimento no cotidiano: as representações sociais na perspectiva da psicologia social.... São Paulo, SP: Brasiliense, 1993. 
VELÁZQUEZ, Cesáreo M. Modelos de uso de la computadora en la escuela [on line]. Disponível na internet: URL <http://investigacion.ilce.edu.mx/>. Acesso em: 08/02/2005.

JOÃO RICARDO FREIRE DE MELO

Programa de Pós-graduação em Ensino de Ciências Naturais e Matemática Universidade Federal do Rio Grande do Norte E-mail: jffmelo@yahoo.com 